\title{
Psychopatholgy, fundamental assumptions and CD-4 T lymphocyte counts in HIV- positive patients
}

\author{
F Vink', S Suliman², N Buck ${ }^{3}$, M Kidd ${ }^{4}$, S Seedat ${ }^{2}$ \\ 1Department of Clinical Psychology, University of Amsterdam, The Netherlands \\ 2Department of Psychiatry, University of Stellenbosch and the MRC Unit on Anxiety and Stress Disorder, Stellenbosch, South Africa \\ 3Maastricht University, Department of Medical, Clinical and Experimental Psychology \& Erasmus MC, Department of Forensic Psychiatry, \\ Maastricht, The Netherlands \\ ${ }^{4}$ Department of Statistical Consultation, University of Stellenbosch, Stellenbosch, South Africa
}

\begin{abstract}
Objective: We investigated whether psychopathology in HIV-positive patients was associated with more negative fundamental assumptions than in healthy controls. In addition, we explored whether psychopathology and negative fundamental assumptions in HIV-positive patients were associated with lower CD4 T-lymphocyte counts. Method: Self-rating questionnaires to assess depressive symptoms, posttraumatic stress symptoms, alcohol abuse, general psychopathology and fundamental assumptions, were completed by 123 HIV-positive patients and 84 uninfected clinic attendees at three primary health care clinics in the Western Cape, South Africa. CD4 T-lymphocyte counts were obtained from chart records. Results: HIV-positive patients reported more depressive and posttraumatic symptoms than uninfected individuals. However when controlling for socio-economic status, the number of traumatic events experienced and other potential confounds, no differences remained. Fundamental assumptions (FA) were mainly positive in both HIV-positive patients and controls and no correlations were found between fundamental assumptions, psychiatric symptoms and CD4 levels. However, in infected patients FA and psychopathology were negatively associated with all participants scoring in the positive range of the FA scale. Conclusion: The positive scores on the FA scale indicate that positive assumptions are related to less psychopathology. Longitudinal studies investigating the association between the valence of fundamental assumptions and HIV morbidity are needed.
\end{abstract}

Key words: Fundamental Assumptions; HIV; Psychopathology

Received: 06-07-2009

Accepted: 02-09-2009

\section{Introduction}

A high prevalence of psychiatric morbidity has been observed in HIV-positive patients, with the most common psychiatric diagnosis being found to be major depressive disorder. Studies have shown lifetime prevalence rates of up to $40 \% .^{1-5}$ Other psychiatric disorders that have frequently been documented in infected individuals are posttraumatic stress disorder (PTSD) ${ }^{5-7}$, other anxiety and adjustment disorders ${ }^{8,9}$, and substance use disorders. ${ }^{10}$
The presence of psychopathology has been associated with faster progression to AIDS. ${ }^{11,12}$ Progression is marked by a reduction in CD-4 cells (the main lymphocyte t-cells involved in protecting the body against infection). ${ }^{13,14}$ For example, Burack and colleagues reported that high levels of depressive symptoms were associated with a more rapid rate of CD4 lymphocyte decline over 5.5 years in a cohort of $277 \mathrm{HIV}-$ positive men. ${ }^{11}$ In another study an association was found between depressed affect and greater mortality. ${ }^{15}$ Depression was also associated with an elevated risk of HIV progression and mortality in a sample of Tanzanian women. ${ }^{16}$

In addition, it has been proposed that the fundamental psychological damage in persons with a potentially terminal disease such as HIV infection and AIDS results from the shattering of basic underlying assumptions that people hold 
about themselves and the world, prior to diagnosis. ${ }^{17-21}$ This perspective stems from cognitive theories that are useful in understanding the psychological sequelae of trauma victim. ${ }^{22-25}$ In general these theories hold that people, over time, develop a conceptual system that provides them with expectations about the world and themselves. This conceptual system can be represented by a set of assumptions, theories or internal representations that reflect and guide people's interactions in the world and generally enable them to function effectively. At the core of this conceptual system are fundamental assumptions that refer to abstract beliefs about the self, the external world, and the relationship between the two. Psychologically traumatic events, including severe or life-threatening physical illness can challenge these fundamental assumptions and expectations regarding the self and the world, for example when a traumatic event provides new information about the world that may be inconsistent with an individual's preexisting assumptions. JanoffBulman proposed that the more positive and unquestioned an individual's pretrauma beliefs, the more vulnerable they will be to subsequent psychopathology as these positive beliefs are more susceptible to being shattered. ${ }^{25}$ Foa and Riggs argued that individuals who hold extremely negative pretrauma beliefs may also be vulnerable to psychopathology as these beliefs become confirmed by the trauma. ${ }^{23}$ Indeed, several studies have documented that fundamental assumptions about the benevolence of the world, the meaningfulness of the world, and own self-worth, in a variety of trauma survivors, are generally more negative than in those who have not experienced a traumatic event. ${ }^{25}$ Several other investigators have found that negative assumptions in trauma survivors are associated with psychopathology, particularly PTSD. ${ }^{26,27}$ Correcting these assumptions would arguably be necessary to bring about a decline in psychopathological symptoms.

To our knowledge no studies have specifically investigated fundamental assumptions in HIV-positive patients, in particular, whether shattering of assumptions might underlie the predisposition to mental health problems. However, several studies have described the way in which HIV-positive patients ascribe meaning to their lives. ${ }^{17-21,28}$ Finding meaning is thought to be one way for individuals to integrate victimizing events into their belief systems and to (re)establish a positive view of the world. ${ }^{25}$ For example, Farber et al. found that individuals who ascribed a more positive meaning to their illness also reported higher levels of psychological well-being and lower levels of depressed mood, even after controlling for factors such as social support and coping. ${ }^{20}$ Finding positive meaning was also positively correlated with blood CD4 T lymphocyte counts. Additionally, in a study by Bower et al. it was found that HIV-positive patients who found meaning after an AIDS-related bereavement showed no mean decline in CD4 counts over a 2- to 3-year follow up period, in contrast to patients who did not find meaning and showed a decline in CD4 counts at follow-up. ${ }^{17}$ Moreover, the discovery of meaning was associated with a lower rate of AIDS-related mortality over a 4- to 9- year follow-up period.

The present study was designed to explore the fundamental assumptions of HIV-positive patients and to assess whether psychopathology (e.g. PTSD, depression, substance abuse) was associated with more negative fundamental assumptions. A secondary aim was to investigate whether psychopathology and fundamental assumptions were associated with a lower CD4 count.

\section{Method \\ Subjects}

Between January and June 2005, 123 HIV-positive patients between the ages of 18 and 65 were recruited at three primary healthcare clinics in the Western Cape, South Africa. HIV positive patients who were found to be cognitively impaired and HIV-positive mothers in the first 6 months of the postpartum period (to exclude the possibility of postnatal depression) were excluded from participation. For comparison purposes, 84 HIV-negative individuals (negative status was based on participants' own reporting of their HIV status) who attended these clinics for minor physical injuries, and who were in the same age range, were also recruited. HIVnegative participants who suffered from any serious medical illness (e.g. cancer, heart disease) were excluded.

\section{Procedure}

An initial screening was conducted to assess eligibility. This included a short interview on demographic and medical information, as well as a brief cognitive assessment in HIVpositive patients. Informed consent was obtained from all participants and several self-report measures were administered (see below). The assessment lasted approximately 45 minutes in total and participants were reimbursed an amount of ZAR 30.00 (\$5.00). The study was approved by the University of Stellenbosch, faculty of health sciences, research ethics committee.

\section{Measurements}

\section{- Demographic and medical information}

All participants completed a demographic questionnaire containing information on age, gender, education, employment, income, marital status, ethnicity, and past and current medical and psychiatric history.

\section{- Cognitive Assessment}

Cognitive impairment was assessed with the Mini-Mental State Examination (MMSE) and the HIV Dementia Scale (HDS). The MMSE is the most widely used instrument to screen for cognitive impairment. ${ }^{29}$ The scale's psychometric properties were thoroughly reviewed by Tombaugh and McIntyre, who found moderate-to-high levels of reliability, and good criterion and construct validity. ${ }^{30}$

The HDS is a brief but sensitive screening instrument to identify HIV-positive patients at risk for dementia ${ }^{31}$ and is widely used in clinical and research settings. ${ }^{32,33}$ Sensitivity and specificity rates have been reported at $80 \%$ and above in clinical samples. ${ }^{31,34,35}$ In a recent study in a South African sample of HIV-patients who were screened with the HDS, on ROC curve analysis a cut-off of $<$ or $=10$ yielded a sensitivity of $80 \%$, specificity of $80 \%$, and discriminated between the presence and absence of cognitive impairment $90 \%$ of the time. ${ }^{36}$

\section{- Fundamental assumptions}

Fundamental assumptions of infected and uninfected individuals were assessed using the Trauma Relevant Assumptions Scale (TRAS). ${ }^{36}$ The TRAS is a newly developed 31 item self-report measure that assesses trauma relevant assumptions. The questionnaire consists of two scales: 'Assumptions about Self' (ASelf) and 'Assumptions about the World' (AWorld). The items 
of ASelf refer to 'self-image' and 'trust in oneself'. The items of AWorld refer to 'safety and justice in the world', 'trustworthiness of others' and 'controllability of negative events'. Two opposite and extreme versions of each assumption (an extreme negative and an extreme positive version) are placed at the ends of a 100 $\mathrm{mm}$ visual analogue scale. Participants are asked to indicate to what extent they agree with the assumption by marking the line in the appropriate place. For example, "The world is always safe" (the extreme positive version of the assumption) will be placed at one end and the assumption "The world is never safe" (the extreme negative version of the assumption) will be placed at the other end of the scale. Scores range from -50 (extreme negative) to +50 (extreme positive). The psychometric properties of the TRAS have recently been examined in a Dutch sample of 309 adult volunteers and in a sample of 185 traumatized individuals. Results suggest that the TRAS is a valid and reliable instrument that is strongly related to symptoms of PTSD, depression and general psychopathology. ${ }^{37}$

For the present study, the TRAS was translated into English, Afrikaans and Xhosa. First, the TRAS was translated from Dutch to English by a native English speaker. Subsequently the English version was independently back-translated into Dutch in order to verify the equivalence of the translation. The Afrikaans and Xhosa versions were translated from the English version by native Afrikaans and Xhosa speakers. These versions were also independently back-translated into English.

\section{- Traumatisation and PTSD}

The Life Events Checklist (LEC), developed by the National Center for Posttraumatic Stress Disorder, is a 16-item list to identify events that would qualify as traumatic or life threatening as defined by the DSM-IV. ${ }^{38}$ Study participants who endorsed witnessing or experiencing one or more of the events also completed the Harvard Trauma Questionnaire (HTQ). The Harvard Trauma Questionnaire (part IV) is a 30item self-rating questionnaire, suited for use in cross-cultural populations, that screens for the presence of PTSD. ${ }^{39}$

\section{- Depressive Symptoms}

Depression was assessed using the Center for Epidemiological Studies Depression Scale (CES-D), a 20-item self-rating scale that assesses current levels of depression. ${ }^{40}$ It has been validated for use in both community and clinic settings ${ }^{41-44}$ and cross-culturally. ${ }^{45-47}$ It has also been used previously in black South African students with adequate reliability and validity. ${ }^{48}$

\section{- Substance Use}

Alcohol use was measured using the Alcohol Use Disorders Identification Test (AUDIT). This is a 10-item, self-rating questionnaire that assesses hazardous drinking and was developed and validated by the World Health Organisation (WHO) in a cross-national study. ${ }^{49}$

\section{- General Psychopathology}

General psychopathology was assessed using the K10. This is a 10-item scale that can be used within primary health care settings as a screening scale for mental disorder and a measure of non-specific psychological distress. 50 The Kl0 has shown consistent psychometric properties in large epidemiologic studies. ${ }^{50}$

\section{- CD4 T lymphocyte count}

CD4 T lymphocyte count data were obtained from clinic records of HIV infected patients. CD4 T lymphocytes were determined by two-color (Leu3+ Leu4+) flow cytometry on whole blood. They are reported as absolute number of CD4 T lymphocytes per cubic millimetre of peripheral blood.

\section{Statistical analysis}

General descriptive statistics were used to describe demographic characteristics and medical information. To test for group differences on demographic characteristics, student's two tailed t-tests were used for continuous variables (age, number of traumatic events), Mann-Whitney U tests for ordinal variables (i.e. education, income) and chi-square analyses were used for nominal variables (i.e. gender, ethnicity, marital status). A reliability analysis was conducted on the TRAS subscales (as the TRAS has not been administered in a South African population) using Cronbach's alpha.

Mean group scores on psychopathology scales and TRAS subscales were also compared using student's two tailed ttests and Mann-Whitney U tests for scores that were not normally distributed. Additionally, analyses of covariance were carried out controlling for possible confounding variables (i.e. number of traumas experienced, prior psychological difficulties $(\mathrm{Y} / \mathrm{N})$ ).

Next, exploratory bivariate Pearson correlations were calculated between mean psychopathology scale scores and TRAS subscale scores for the HIV-positive group. Spearman's rho correlations were calculated when scores were not normally distributed. Spearman's rho correlations were also calculated for mean psychopathology scale scores, TRAS subscale scores and CD 4 counts, controlling for age, duration of illness and antiretroviral treatment. Participants with missing items on a scale were excluded from analysis of that particular scale, which resulted in a slight variation in sample size across analyses. The number of excluded participants varied between 1 and 8 per scale.

All p values were 2-sided ( $p$ values of $<.05$ were considered statistically significant) and adjustments were not made for multiple comparisons as this was an exploratory study. Statistical analyses were performed using version 12.0.1 of the Statistical Package for the Social Sciences and Statistica version 8.

\section{Results}

\section{Subject description}

Demographic and medical information is presented in Table I. The groups did not differ on mean age and marital status. However, the HIV-positive group had significantly more females and the two groups differed significantly on ethnicity, education, employment status and income. Although all participants had experienced at least one traumatic event, the two groups differed with respect to the amount of trauma exposure, with the HIV-positive group having experienced more traumatic events than the comparison group. Subsequent group comparisons were therefore carried out using analysis of covariance controlling for gender, ethnicity, education, employment, income and trauma exposure. The majority of HIV-positive participants had been diagnosed more than 2 years prior to this study and just under half endorsed being on anti-retro-viral treatment. 


\section{Table I: Subject Characteristics}

\begin{tabular}{|c|c|c|c|}
\hline $\begin{array}{l}\text { Demographic } \\
\text { Characteristics }\end{array}$ & $\begin{array}{l}\text { HIV-positive group } \\
N=123\end{array}$ & $\begin{array}{l}H I V \text {-negative group } \\
N=84\end{array}$ & Group Differences \\
\hline Age & $\begin{array}{l}n=121 \\
\text { Mean }=33.26 \\
S D=6.74\end{array}$ & $\begin{array}{l}n=79 \\
\text { Mean }=32.70 \\
S D=10.40\end{array}$ & $p=0.06$ \\
\hline $\begin{array}{l}\text { Gender**} \\
\text { Male } \\
\text { Female }\end{array}$ & $\begin{array}{l}n=29(23.6 \%) \\
n=91(74 \%)\end{array}$ & $\begin{array}{l}n=34(40.5 \%) \\
n=50(59.5)\end{array}$ & $p=0.01$ \\
\hline $\begin{array}{l}\text { Marital status } \\
\text { Single } \\
\text { Relationship } \\
\text { Married } \\
\text { Divorced / Widowed }\end{array}$ & $\begin{array}{l}n=33(26.8 \%) \\
n=51(41.5 \%) \\
n=33(26.8 \%) \\
n=3(2.4 \%)\end{array}$ & $\begin{array}{l}n=22(26.2 \%) \\
n=22(26.2 \%) \\
n=35(41.7 \%) \\
n=4(4.8 \%)\end{array}$ & $p=0.06$ \\
\hline $\begin{array}{l}\text { Ethnicity }^{\star *} \\
\text { Black } \\
\text { Coloured } \\
\text { Asian + White }\end{array}$ & $\begin{array}{l}n=94(76.4 \%) \\
n=24(19.5 \%) \\
n=3(2.4 \%)\end{array}$ & $\begin{array}{l}n=18(21.4 \%) \\
n=61(72.6 \%) \\
n=5(6.0 \%)\end{array}$ & $p<0.01$ \\
\hline $\begin{array}{l}\text { Education/grade }^{1 * \star} \\
\text { Grade } 1 \text { - Grade } 12 \\
\text { Diploma/Degree }\end{array}$ & $\begin{array}{l}n=116(94.3 \%) \\
n=1(0.8 \%)\end{array}$ & $\begin{array}{l}n=46(54.8 \%) \\
n=5(6.0 \%)\end{array}$ & $p<0.01$ \\
\hline $\begin{array}{l}\text { Employment Status**} \\
\text { Working } \\
\text { Unemployed } \\
\text { Disability / Pension }\end{array}$ & $\begin{array}{l}n=33(26.8 \%) \\
n=37(30.1 \%) \\
n=41(33.3 \%)\end{array}$ & $\begin{array}{l}n=69(82.1 \%) \\
n=14(16.7 \%) \\
n=1(1.2 \%)\end{array}$ & $p<0.01$ \\
\hline $\begin{array}{l}\text { Income per week }{ }^{* *} \\
\text { O-R200 } \\
\text { R201-R500 } \\
\text { R501-R1000 } \\
\text { >R1000 }\end{array}$ & $\begin{array}{l}n=78(63.4 \%) \\
n=20(16.3 \%) \\
n=9(7.3 \%) \\
n=4(3.3 \%)\end{array}$ & $\begin{array}{l}n=28(33.3 \%) \\
n=23(27.4 \%) \\
n=17(20.2 \%) \\
n=14(16.7 \%)\end{array}$ & $p<0.01$ \\
\hline Characteristics & $\begin{array}{l}\text { HIV-positive group } \\
N=123\end{array}$ & $\begin{array}{l}H I V \text {-negative group } \\
N=84\end{array}$ & Significance \\
\hline LEC $^{\star \star}$ (number of traumatic events) & $\begin{array}{l}n=119 \\
M=4.68 \\
S D=3.26\end{array}$ & $\begin{array}{l}n=82 \\
M=3.29 \\
S D=2.9\end{array}$ & $p<0.01$ \\
\hline $\begin{array}{l}\text { Prior psychological difficulties } \\
\text { No } \\
\text { Yes }\end{array}$ & $\begin{array}{l}n=106(86.2 \%) \\
n=13(10.6 \%)\end{array}$ & $\begin{array}{l}n=78(92.9 \%) \\
n=6(7.1 \%)\end{array}$ & $p=0.36$ \\
\hline $\begin{array}{l}\text { Time since HIV+ diagnose } \\
0-1 \text { year } \\
1-2 \text { years } \\
>2 \text { years }\end{array}$ & $\begin{array}{l}n=24(19.5 \%) \\
n=30(24.4 \%) \\
n=67(54.6 \%) \\
\text { Mean: } 40.23 \text { months } \\
\text { SD: } 34.13\end{array}$ & & \\
\hline $\begin{array}{l}\text { CD4 count } \\
\text { CD4 } \leq 200 \mathrm{~m} / \mathrm{L} \\
\text { CD4 } 201 \mathrm{~m} / \mathrm{L}-499 \mathrm{~m} / \mathrm{L} \\
\text { CD4 } \geq 500 \mathrm{~m} / \mathrm{L}\end{array}$ & $\begin{array}{l}n=46(37.4 \%) \\
n=49(39.8 \%) \\
n=12(9.8 \%) \\
\text { Mean: } 276.4 \\
\text { SD: } 199.5\end{array}$ & & \\
\hline $\begin{array}{l}\text { Antiretroviral Treatment } \\
\text { No } \\
\text { Yes }\end{array}$ & $\begin{array}{l}n=45(36.6 \%) \\
n=61(49.6 \%)\end{array}$ & & \\
\hline
\end{tabular}




\section{Internal consistency of TRAS subscales}

Cronbach's alpha estimates of internal consistency of the subscales of the TRAS were strong for ASelf (Cronbach's alpha $=.80$ ) and weak for AWorld (Cronbach's alpha = .47). Cronbach's alpha estimates were recalculated for AWorld, with each item of the scale deleted, however no difference was found. The correlation between the two subscales was .09. Subsequent analysis was therefore only carried out for the TRAS ASelf subscale.

\section{Prevalence of psychopathological symptoms}

As expected, the HIV-positive group scored significantly higher on the CES-D than the HIV-negative group and had significantly more PTSD symptoms. The difference with respect to depressive symptoms remained significant after controlling for gender and education. However, no significant difference remained when controlling for ethnicity, employment, income and trauma exposure. For PTSD symptoms, the difference between the groups also remained significant after controlling for gender and education. However, significance disappeared when controlling for ethnicity, employment, income and trauma exposure. There was no significant difference on general psychopathology, and, contrary to expectation, the control group scored significantly higher on the scale for hazardous alcohol consumption than the HIV-positive group, even after controlling for confounding variables. Table II shows the prevalence of depressive symptoms, PTSD symptoms, alcohol abuse and general psychopathology in both groups, with covariates taken into account.

\section{Fundamental assumptions}

Table II shows means and standard deviations of the TRAS subscale ASelf for both groups. There were no significant group differences. As seen in Figure 1, the variance of ASelf in

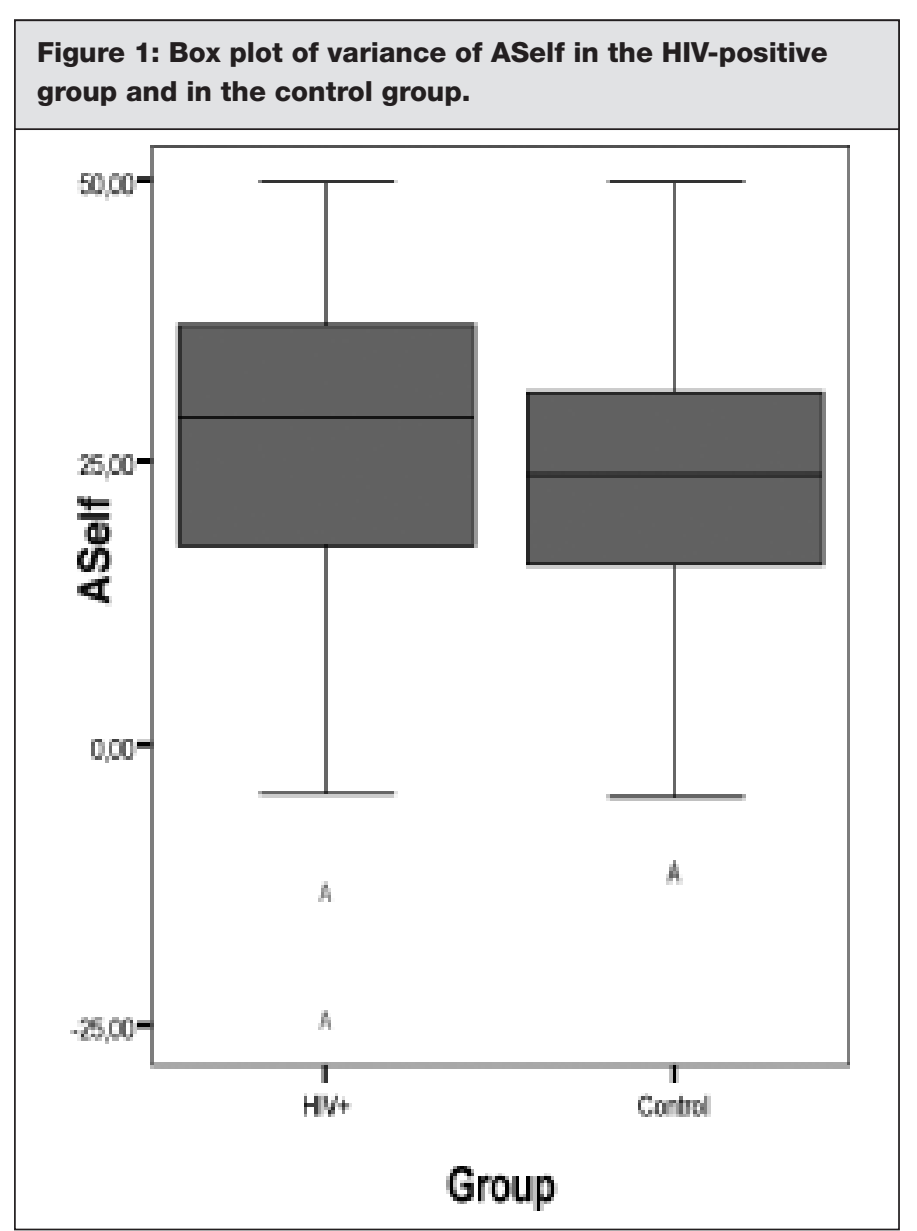

both subject groups is high. In the HIV-positive group the minimum score on A.Self was -25.26 and the maximum score was +50 . In the HIV-negative group the scores on ASelf range from -12.26 to +50 . Most scores were in the positive range.

\begin{tabular}{|c|c|c|c|}
\hline & $\begin{array}{l}\text { HIV-positive group } \\
N=123\end{array}$ & $\begin{array}{l}\text { Control group } \\
N=84\end{array}$ & Significance \\
\hline $\begin{array}{l}\text { CES-D } \\
\text { (Depressive Symptoms) }\end{array}$ & $\begin{array}{l}M=15.82 \\
S D=11.57 \\
n=121\end{array}$ & $\begin{array}{l}M=11.35 \\
S D=10.80 \\
n=81\end{array}$ & $p=0.89$ \\
\hline $\begin{array}{l}\text { Harvard Trauma Scale } \\
\text { (PTSD Symptoms) }\end{array}$ & $\begin{array}{l}M=50.54 \\
S D=17.07 \\
n=120\end{array}$ & $\begin{array}{l}M=43.49 \\
S D=19.54 \\
n=83\end{array}$ & $p=0.27$ \\
\hline $\begin{array}{l}\text { AUDIT }^{\star *} \\
\text { (Alcohol abuse) }\end{array}$ & $\begin{array}{l}M=2.83 \\
S D=5.93 \\
n=120\end{array}$ & $\begin{array}{l}M=6.42 \\
S D=8.00 \\
n=83\end{array}$ & $p=0.01$ \\
\hline $\begin{array}{l}\text { K10 } \\
\text { (General Psychopathology) }\end{array}$ & $\begin{array}{l}M=21.22 \\
S D=7.49 \\
n=121\end{array}$ & $\begin{array}{l}M=19.49 \\
S D=8.10 \\
n=81\end{array}$ & $p=0.57$ \\
\hline $\begin{array}{l}\text { TRAS (ASelf) } \\
\text { (Fundamental Assumptions) }\end{array}$ & $\begin{array}{l}M=26.59 \\
S D=13.75 \\
n=115\end{array}$ & $\begin{array}{l}M=22.98 \\
S D=13.44 \\
n=78\end{array}$ & $p=0.15$ \\
\hline
\end{tabular}


There was no difference on ASelf scores between those who had been diagnosed in the last 12 months and those who had been diagnosed prior to that $(p=0.855)$, nor was there a difference between those who were on ARV treatment and those not on treatment $(\mathrm{p}=0.532)$.

\section{Fundamental assumptions, psychopathology and CD4-count} Table III shows the correlations for depressive symptoms, PTSD symptoms, alcohol abuse, general psychopathology and the TRAS ASelf subscale for the HIV-positive group. As expected, all correlations were negative for ASelf. Thus, more negative scores on ASelf were associated with more depressive symptoms, PTSD symptoms, alcohol abuse and general psychopathology. This held true when the analysis was conducted for all participants as well. However, only 7.5 $\%$ of the variance of ASelf was explained by PTSD symptoms $\left(r^{2}=0.08\right)$. In contrast, the relation between ASelf and general psychopathology was strong, with $18.6 \%$ of the variance explained. No significant correlations were found between the TRAS ASelf subscale and CD4 count or between psychopathology scale scores and CD4 count.

\section{Table III: Correlations between TRAS subscale ASelf, CES-D,} AUDIT, HTS, K10 and CD4 count

\begin{tabular}{|l|l|l|}
\hline & Assumptions about Self & CD4-count \\
\hline CES-D (Depression) & $-.243^{* *}$ & -.054 \\
AUDIT (Alcohol use) & -.108 & -.160 \\
HTS (PTSD) & $-.275^{\star *}$ & -.015 \\
K10 (Psychopathology) & $-.432^{* *}$ & .020 \\
Assumptions about Self & & -.187 \\
\hline${ }^{*}$ Correlation is significant at the 0.05 level (2-tailed) \\
${ }^{* *}$ Correlation is significant at the 0.01 level (2-tailed) \\
\hline
\end{tabular}

\section{Discussion}

First, we found that fundamental assumptions of HIV-positive patients regarding 'self' were no more negative than uninfected controls. Instead, the fundamental assumptions were relatively positive in both groups. Notably, in the HIVpositive group there were almost no negative assumptions reported. However, fundamental assumptions and psychopathology were negatively related in the total sample, as well as in the HIV-positive patients, indicating that more psychopathology was related to less positive assumptions or that more positive assumptions were related to less psychopathology. Second, HIV-positive patients had more depressive symptoms and posttraumatic stress symptoms than uninfected controls. However after controlling for ethnicity, socio-economic status and number of traumatic events, group differences were no longer significant. Although there were no significant group differences in psychopathology, in the HIV-positive group more than one third scored above the cut-off score for depression and more than $10 \%$ above the cut-off for PTSD. These findings are consistent with previous studies on prevalence rates of these disorders in HIV infected patients. ${ }^{51,52}$ Notably, uninfected controls had higher rates of alcohol abuse than HIV-positive patients, even after controlling for potential confounds. Third,
CD4 count bore no relationship either to fundamental assumptions or to psychopathology.

The findings of the present study are not consistent with the study of Buck et al. which found a strong relationship between the TRAS and symptoms of PTSD, depression and psychopathology. ${ }^{37}$ The finding of few negative fundamental assumptions, and mainly positive assumptions, in HIV infected patients is surprising. In the aforementioned Dutch study where the TRAS was used both negative and positive assumptions were evident in healthy adult volunteers and in traumatized individuals. A possible explanation for our finding is that since the majority of HIV positive participants in this sample had been diagnosed over 2 years prior to the study, they may have already re-ascribed meaning and (re)established a positive view of the world and self. In addition, social desirability could have influenced response tendencies, and the cross-sectional design of this study does not allow for causal inference. More rigorous exploration of whether shattering of fundamental assumptions could be underlying the predisposition to mental health problems in HIV-positive patients, requires a longitudinal design. Fundamental assumptions held prior to an HIV diagnosis could then be assessed retrospectively and assessment of illness progression (e.g decline in CD4 counts) and their impact on negative assumptions could be explored.

\section{Limitations}

There are several limitations that need to be considered when interpreting these findings. First, HIV-positive patients and uninfected controls differed on several sociodemographic parameters (eg. gender, ethnicity, socio-economic status). However, these were controlled for when comparing the 2 groups. Second, psychiatric symptomatology and fundamental assumptions were assessed using self-rating scales, thus possible biases including social desirability or certain response tendencies, may have made the findings less valid and reliable. That said, these measures demonstrate reliability and validity in HIVpositive samples. ${ }^{53}$ Third, regarding the assessment of fundamental assumptions, validity and reliability of the TRAS have only been determined in a Dutch national sample and so it is questionable whether the TRAS is a suitable instrument for non-western populations. The weak internal consistency of the 'world' scale of the TRAS, underlines this consideration. Further validation of the TRAS in cross-cultural samples is necessary. A final limitation is that determination of CD4 counts in relation to psychiatric symptoms and fundamental assumptions were not all done in real-time.

\section{Conclusion}

In conclusion, although HIV-positive patients reported more symptoms of depression and PTSD than uninfected participants, the difference was not statistically significant and these symptoms could not be specifically attributed to an HIV diagnosis. Moreover, strongly negative assumptions were not evident in this sample and were not associated with the presence of psychiatric related morbidity. Further work is needed to explore the association of assumptions (positive and negative) in the context of trauma, negative life experiences, and psychiatric and physical sequelae in HIVinfected patients. 


\section{Acknowledgments}

This research was conducted as part of F. Vink's MSc thesis. M. Kindt is gratefully acknowledged for her support with this work. We are grateful to L. de Villiers, S. Parker and L. Plaatjies (from the MRC Anxiety Disorders Unit) for their assistance with data collection and to M. Spiering (University of Amsterdam) for his help with the statistical analysis. This study was supported by the MRC Unit on Anxiety Disorders, the Schuurman Schimmel-van Outeren Foundation, Bekker La Bastide Funds, AUV funds, STUNT scholarship and Internationalisation funds Psychology, University of Amsterdam.

\section{References}

1. Ciesla JA, Roberts JE. Meta-analysis of the relationship between HIV infection and risk for depressive disorders. Am J Psychiatry 2001; 158:725-730

2. Dew MA, Becker JT, Sanchez J, et al. Prevalence and predictors of depressive, anxiety and substance use disorders in HIV-infected and uninfected men: A longitudinal evaluation. Psychol Med 1997;27:395-409.

3. Fleishman JA, Fogel B. Coping and depressive symptoms among people with AIDS. Health Psychol 1994;13:156-169.

4. MCDaniel JS, Fowlie E, Summerville MB, Farber EW, Cohen-Cole SA. An assessment of rates of psychiatric morbidity and functioning in HIV disease. Gen Hosp Psychiatry 1995; 17:346-352.

5. Olley BO, Gxamza F, Seedat S, et al. Psychopathology and coping in recently diagnosed HIVIAIDS patients - the role of gender. SAMJ 2003;93:928-931.

6. Kelly B, Raphael B, Judd F, Kernutt G, Burnett P, Burrows G. Posttraumatic stress disorder in response to HIV infection. Gen Hosp Psychiatry 1998;20:345-352.

7. Martin L, Kagee A. Lifetime and HIV-related PTSD among persons recently diagnosed with HIV. AIDS Behav, 2008.

8. Holmes WC, Bix B, Meritz M, Turner J, Hutelmyer C. Human Immunodeficiency Virus (HIV) infection and quality of life: The potential impact of Axis I psychiatric disorders in a sample of 95 HIV seropositive men. Psychosom Med 1997;59:187-192.

9. Rabkin JG, Johnson J, Lin SH, et al. Psychopathology in male and female HIV-positive and negative injecting drug users: Longitudinal course over 3 years. AIDS 1997;11:507-515.

10. Galvin FH, Bing EG, Fleishman JA, et al. The prevalence of alcohol consumption and heavy drinking among people with HIV in the United States: Results from the HIV Cost and Services Utilization Study. J Stud Alcohol 2002;63:1 19-186.

11. Burack JH., Barrett DC, Stall RD, Chesney MA, Ekstrand ML, Coates TJ. Depressive symptoms and CD4 lymphocyte decline among HIV-infected men. JAMA 1993;270:2568-2573.

12. Leserman J, Petitto JM., Gu H, et al. Progression to AIDS, a clinical AIDS condition and mortality: Psychosocial and physiological predictors. Psychol Med 2002;32:1059-1073.

13. Nott KA, Vedhara K, Spickett GP. Psychology, immunology and HIV. Psychoneuroendocrinology 1995;20:451-474

14. Begtrup K, Melbye M, Biggar RJ, Goedert JJ, Knudsen K, Andersen $P K$. Progression to acquired immunodeficiency syndrome is influenced by CD4 T-lymphocyte count and time since seroconversion. Am Journal Epidemiol 1997;145:629-635.

15. Mayne TJ, Vittinghoff E, Chesney MA, Barrett DC, Coates TJ. Depressive affect and survival among gay and bisexual men infected with HIV. Arch Intern Med 1996; 156:2233-2238.
16. Antelman G, Kaava S, Wei R., et al. Depressive symptoms increase risk of HIV disease progresssion and mortality among women in Tanzania. Journal of Acquired Immune Deficiency Syndromes 2007;44:470-477.

17. Bower JE, Kemeny ME, Taylor SE, Fahey JL. Cognitive processing, discovery of meaning, CD4 decline, and AIDS-related mortality among bereaved HIV-serpositive men. J Consult Clin Pychol 1998; 66:979-986.

18. Crossley LM. Women living with a long-term HIV positive diagnosis: Problems, concerns and ways of ascribing meaning. Women's Studies International Forum 1998;21:521-533.

19. Davies ML. Shattered assumptions: Time and the experience of longterm HIV positivity. Soc Sci Med 1997;44:561-571.

20. Farber EW, Mirsalimi H, Williams KA, MCDaniel JS. Meaning of Illnes.S and Psychological Adjustment to HIVIAIDS. Psychosomatics 2003:44:485-491.

21. Schwartzberg SS. Struggling for meaning: How HIV-positive Gay men make sense of AIDS. Professional Psychology: Research and Practice 1993:24:483-490.

22. Ehlers A, Clark DM. A cognitive model of posttraumatic stress disorder. Behav Res Ther 2000;38:319-345.

23. Foa EB, Riggs DS. Posttraumatic stress disorder and rape. In: J Oldman \& A Tasman. Annu Rev Psychiatry 1993;12:273-303.

24. Horowitz MJ, Reidbord SP. Memory, emotion, and response to trauma. In: S. Christianson (Ed). The handbook of emotion and memory: research and theorie. New J.ersey: Lawrence Erlbaum Associates, Inc, 1992

25. Janoff-Bulman R. Shattered Assumptions: Towards a New Psychology of Trauma. New York: Free Press, 1992.

26. Ali T, Dunmore E, Clark D, Ehlers A. The role of negative beliefs in posttraumatic stress disorder: a comparison of assault victims and non victims. Behav Cogn Psychotherapy 2002;30:249-257.

27. Foa EB, Ehlers A, Clark DM, Tolin DF, Orsillo SM. The Posttraumatic Cognitions Inventory (PTCI): Development and validation. Psychol Assess 1999;11:303-314.

28. Ezzy D. Illness narratives: Time, hope and HIV. Soc Sci Med 2000; 50:605-617.

29. Bravo G, Herbert R. Age- and education-specific reference values for the Mini-Mental and Modified Mini-Mental State Examinations derived from a non-demented elderly population. Int J Geriatr Psychiatry 1992;12:1008-1018.

30. Tombaugh TN, McIntry NJ. The Mini-Mental State Examination: A comprehensive review. J Am Geriatr Soc 1992;40:922-935.

31. Power C, Selnes OA, Grim JA, McArthur JC. HIV Dementia Scale: A rapid screening tool. Journal of Acquired Immune Deficiency Syndrome 1995;8:273-278.

32. Chang L, Ernst T, Leonido-Yee, $M$, et al. Highly active antiretroviral therapy reverses brain metabolite abnormalities in mild HIV dementia. Neurology 1999;53:782-789.

33. Chang L, Ernst T, Leonide-Yee M, Speck O. Perfusion MRI detects rCBF abnormalities in early stages of HIV-cognitive motor complex. Neurology 2000;54:389-396.

34. Berghuis JP, Uldall KK, Lalondo, B. Validity of two scales in Identifying HIV-associated dementia. Journal of Acquired Immune Deficiency Syndrome 1999;21:134-140.

35. Childers M, Ellis R, Deutsch R, Wolfson T, Grant I, The HNRC Group. The utility and limitations of the HIV Dementia Scale. J Int Neuropsychol Soc 2003;8:160.

36. Ganasen KA, Fincham D, Smit J, Seedat S, Stein D. Utility of the HIV Dementia Scale (HDS) in identifying HIV dementia in a South African sample. J Neurol Sci 2008;296:62-64. 
37. Buck N, Kindt M, Arntz A, Van den Hout M, Schouten E. Psychometric properties of the Trauma Relevant Assumptions Scale. Journal Anxiety Disord 2008;22:1496-1509.

38. Gray MJ, Litz BT, Hsu JL, Lombardo TW. Psychometric properties of the Life Events Checklist. Assessment 2004;1 1:330-341.

39. Mollica RF, Caspi-Yavin Y, Bollini P, Truong T, Tor S, Lavelle J. The Harvard Trauma Questionnaire. Validating a cross-cultural instrument for measuring torture, trauma and posttraumatic stress disorder in Indochinese refugees. J Nerv Ment Dis 1992;180:1 1 1-6.

40. Radloff LS. The CES-D Scale: A self-report depression scale for research in the general population. Applied Psychological Measurement 1977;1:385-401.

41. Boyd JH, Weissman MM, Thompson WD, Meyers JK. Screening for depression in a community sample. Understanding the discrepancies between depression and diagnostic scales. Arch Gen Psychiatry 1982;39:1195-2000

42. Meyers JK, Weissman MM. Use of a self-report symptom scale to detect depression in a community sample. Am J Psychiatry 1980;137:1081-4

43. Roberts RE, Vernon SW. The Center for Epidemiological Studies Depression Scale: Its use in a community sample. Am J Psychiatry 1983;140:41-6.

44. Weissman MM, Sholomskas D, Pottenger M, Prusoff BA, Locke BZ. Assessing depressive symptoms in five psychiatric populations: A validation study. Am J Epidemiol 1977;106:203-14.

45. Ghubash R, Daradkeh TK, Al Naseri KS, Al Bloushi NB, Al Daheri AM The performance of the Center for Epidemiology Study Depression
Scale (CES-D) in an Arab female community. Int J Soc Psychiatry 2000;46:241-9.

46. Iwata N, Buka S. Race/ethnicity and depressive symptoms: A crosscultural/ethnic comparison among university students in East Asia, North and South America. Soc Sci Med 2002; 55:2243-52.

47. Munet-Vilaro F, Folkman S, Gregorich S. Depressive symptomatology in three Latino groups, West J Nurs Res 1999; 21:209-24.

48. Pretorius TB. Cross-cultural application of the Centre for Epidemiological Studies Depression Scale: A study of Black South African students. Psychol Rep 1991; 69:179-85.

49. Saunders JB, Aasland OG, Babor TF, De la Fuente JR, Grant M. Development of the Alcohol Use Disorders Identification Test (AUDIT): WHO collaborative project on early detection of persons with harmful alcohol consumption - II. Addiction 1993; 88:791-804.

50. Kessler RC, Andrews G, Colpe LJ, et al. Short screening scales to monitor population prevalences and trends in non-specific psychological distress. Psychol Med 2002; 32:959-976.

51. Bganya E. Depressive disorders and symptoms in patients with HIVIAIDS infection. M.Med. Dissertation: Medical University of South Africa, 1999

52. Els C, Boshoff W, Scott W, Strydom W, Joubert G, Van der Rust E. Psychiatric comorbidity in South African HIVIAIDS patients. S Afr Med J 1999;89:992-5

53. Myer L, Smit J, Le Roux L, Parker S, Stein, DJ, Seedat S. Common Mental Disorders among HIV-Infected Individuals in South Africa: Prevalence, Predictors, and Validation of Brief Psychiatric Rating Scales. AIDS Patient Care and STDs 2008;22:47-158.

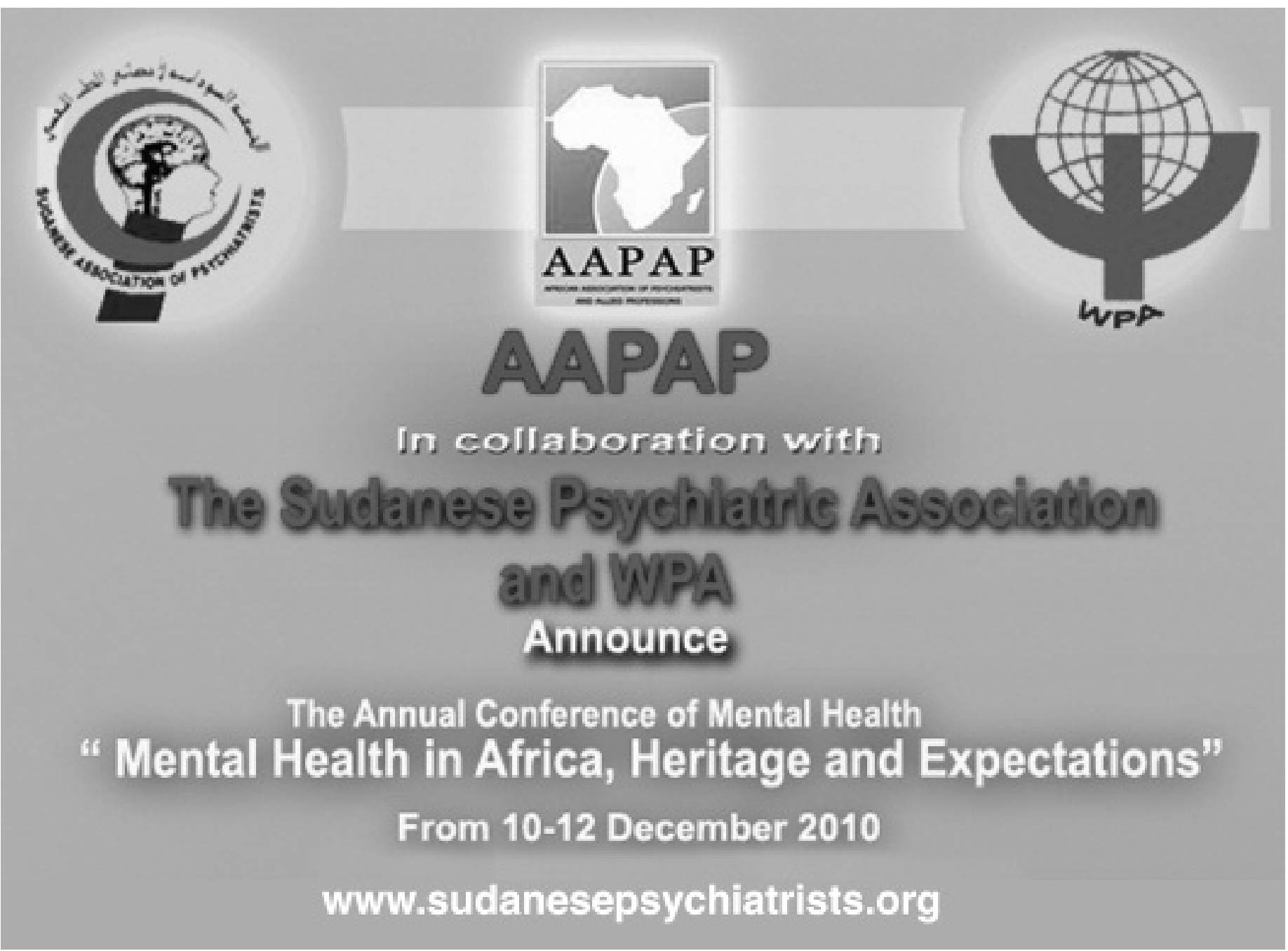

